\title{
Improving Economic Conditions Matter for Mortality: Changes in Local Economic Distress Associated with Mortality Among Medicare Fee-for-Service Beneficiaries Between 2003 and 2015
}

$J$ Gen Intern Med 37(1):249-51 DOI: $10.1007 / \mathrm{s} 11606-020-06410-z$

(c) Society of General Internal Medicine 2021

\section{INTRODUCTION}

Among Medicare fee-for-service beneficiaries, higher local economic distress is associated with less recommended care receipt ${ }^{1}$ higher end-of-life spending among decedents; ${ }^{2}$ and higher per-capita spending, lower care quality, and higher mortality rates. ${ }^{3}$ We sought to determine whether spending and mortality rate disparities changed over time and within communities where local economic distress changed dramatically.

\section{METHODS}

From the Dartmouth Atlas Project, ${ }^{4}$ we obtained 2003-2015 hospital service area (HSA)-level data on price- and age-, sex, and race (ASR)-adjusted total annual per-capita Medicare Part A+B expenditures and ASR-adjusted mortality rates for fee-for-service enrollees.

From the Economic Innovation Group (EIG), we obtained 2000 and 2015 Distressed Communities Index (DCI) scores at the zip code level. Constructed from seven measures of local economic distress, scores range from 0 (least economically distressed) to $100 .^{1-3}$ For 3412 HSAs, we assigned zip codeenrollee-weighted HSA-level scores to 2000 and 2015 DCI quintiles.

We tracked annual expenditure and mortality rates over time and used enrollee-weighted ANOVA (R, Vienna, Austria) to compare quintile-specific values. We identified HSAs that started in the least or most distressed quintiles in 2000 and compared those that changed at least 2 quintiles by $2015(n=$ 14 and 39, respectively) to those that $\operatorname{did} \operatorname{not}(n=628$ and 603 , respectively).

We obtained all data from publicly available sources; IRB approval was not required.

Received August 28, 2020

Accepted December 7, 2020

Published online January 22, 2021

\section{RESULTS}

Between 2003 and 2015, annual per-capita Part A+B expenditures for the most economically distressed HSAs were 12$13 \%$ higher than those for the least ( $p<0.0001$ for each year); across quintiles, expenditures rose rapidly between 2002 and 2010, then flattened (Fig. 1, left).

Mortality rates declined across all 2000 DCI-defined quintiles; they were substantially higher in the most economically distressed HSAs than in the least $(p<0.0001$ for each year). Between 2003 and 2015, the absolute mortality gap between most and least distressed quintiles increased from 0.76 to $1.13 \%$ (Fig. 2, left).

Enrollees living in areas where local economic conditions substantially worsened between 2000 and 2015 experienced higher ASR-adjusted mortality rates than those where economic conditions remained favorable by a widening margin, from $-0.05 \%$ in 2003 (n.s.) to $0.53 \%$ in $2015(p<0.05)$. Enrollees living in areas where local economic conditions substantially improved experienced significantly lower ASRadjusted mortality rates than those where economic conditions remained unfavorable, with the absolute mortality gap widening over time (from $0.77 \%$ in 2003 to $1.28 \%$ in 2015, $p<$ 0.0001 for each year) (Fig. 2, right). Per-capita spending was higher in HSAs where economic distress decreased than where it remained high $(p<0.01$ in all years save 2006-2010) (Fig. 1 , right).

\section{DISCUSSION}

We found that Medicare fee-for-service enrollees living in the most-economically distressed areas in 2000 consistently experienced higher per-capita expenditures and mortality rates between 2003 and 2015 than those living in the least. Among those living in the most- and least-distressed HSAs, substantial improvement or worsening of local economic conditions was associated with relative decreases or increases in mortality rates, respectively; percapita costs were higher where economic distress dramatically improved. Flattening of cost growth across quintiles since 2010 could be due to convergence in cost growth across high- and low-spending regions ${ }^{5}$ or decreasing decedents' end-of-life care costs during that time. ${ }^{2}$ 


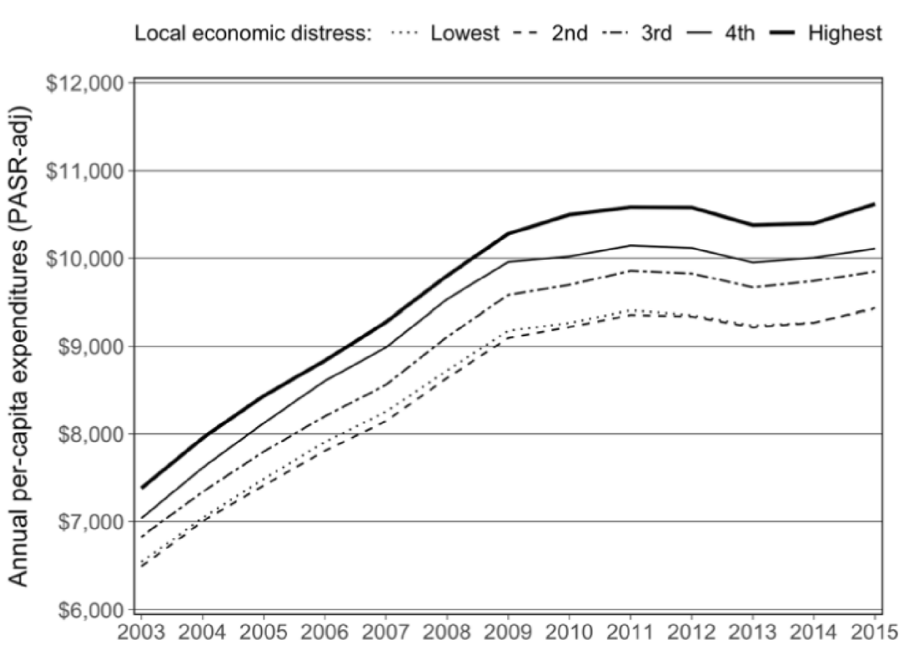

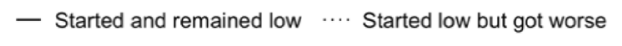

- Started and remained high . Started high and got better

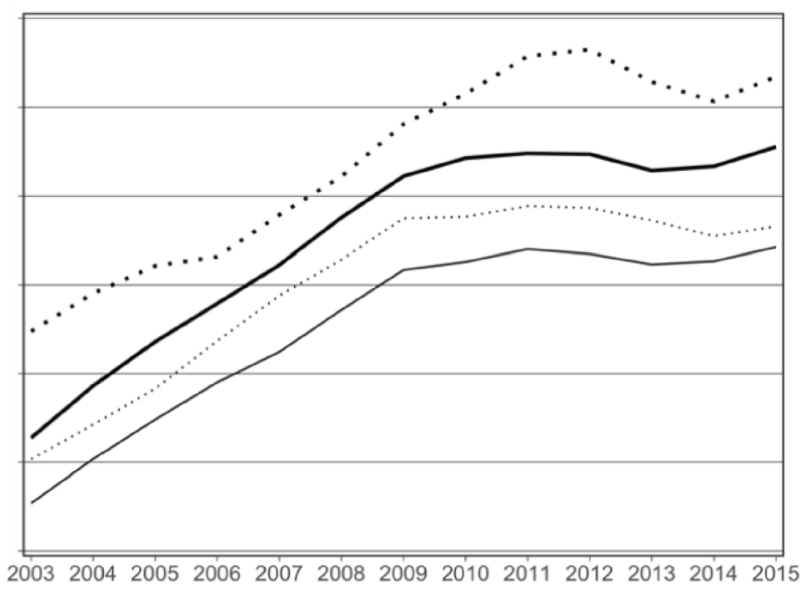

Figure 1 Price-, age-, sex-, and race (PASR)-adjusted per-capita Medicare Part A+B annual expenditures for HSAs grouped by 2000 DCI quintile (left) and grouped by the most- and least-economically distressed HSAs that remained in those categories or experienced dramatic improvements or worsening of local economic conditions (right).

Additional research should explore why there were lower initial mortality rates among HSAs wherein the local economic environment improved dramatically.

Our findings suggest that Medicare fee-for-service beneficiaries living in persistently economically distressed communities face disproportionately high mortality rates. However, substantial improvement in local economic conditions might mitigate that inequity. This research suggests that effective economic development interventions ${ }^{6}$ could confer long-term health benefits in a relatively short time period.

Our study has several limitations. First, our findings are associative, not causative; however, they are based on a natural experiment and random assignment to increasing or decreasing local economic conditions is not possible. Second, our findings apply only to Medicare fee-for-service enrollees and the time period examined; results examining other populations and time periods may differ. Finally, we used EIG's measures of community distress; other measures may generate different results.

Despite these limitations, our findings identified important relationships between changes in local economic distress and long-term mortality rates and confer a mix of anguish and hope: anguish in that these seem inextricably linked; hope in that relative improvement in economic distress may improve health outcomes relatively quickly.
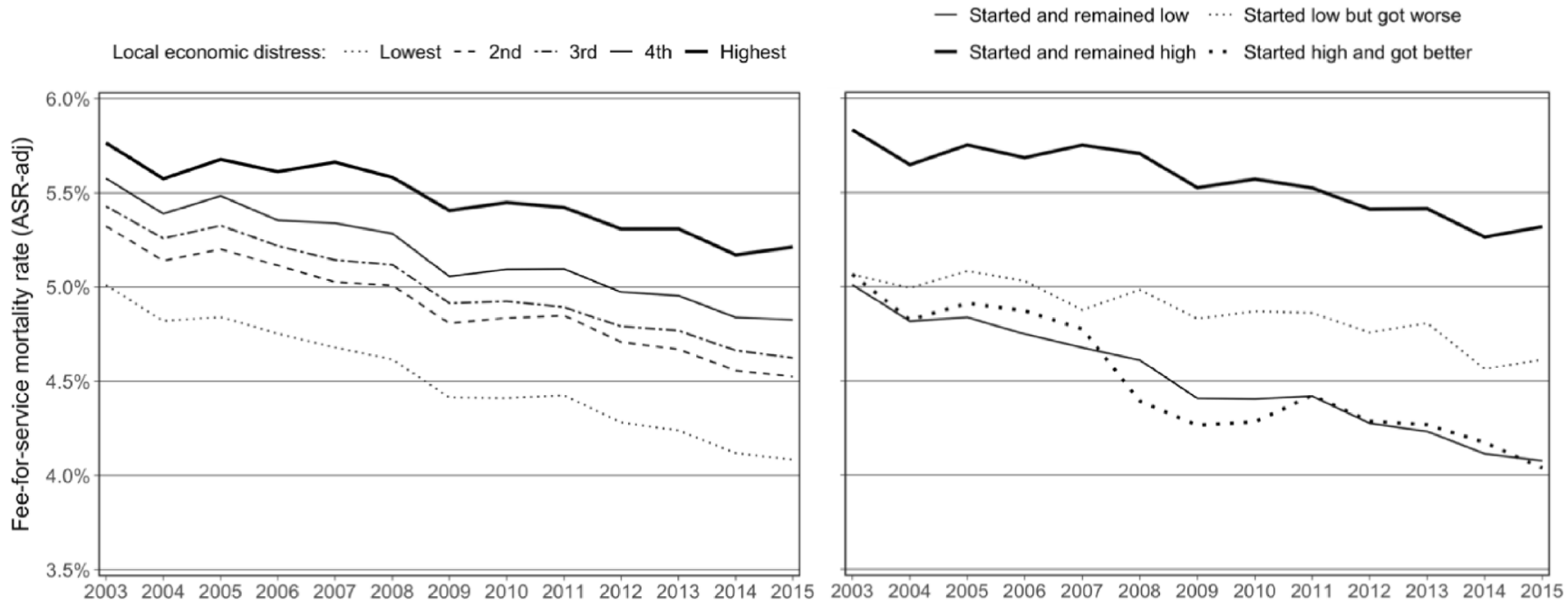

Figure 2 For 2003-2015, annual age-, sex-, and race (ASR)-adjusted fee-for-service Medicare beneficiary mortality rates grouped by local economic distress-defined hospital service area quintiles in 2000 (left) and grouped by the most- and least-economically distressed HSAs that remained in those categories or experienced dramatic improvements or worsening of local economic conditions (right). 
Acknowledgments: This paper used propriety data provided by the Economic Innovation Group. The findings expressed in this article are solely those of the authors and not necessarily those of the Economic Innovation Group. The Economic Innovation Group does not guarantee the reliability of, or necessarily agree with, the information provided herein. The Medicare fee-for-service reimbursement and mortality data used here were obtained from Dartmouth Atlas Data website, which was funded by the Robert Wood Johnson Foundation, The Dartmouth Clinical and Translational Science Institute, under award number UL1TR001086 from the National Center for Advancing Translational Sciences (NCATS) of the National Institutes of Health (NIH), and in part, by the National Institute of Aging, under award number U01AG046830.

Harper O. Wallace, BS ${ }^{1}$

Kenan Fikri, $M S^{2}$

James $N$. Weinstein, $D O, M S^{3,4,5,6}$

William B. Weeks, $M D, P h D, M B A^{3}$

${ }^{1}$ École Normale Supérieure, PSL Research University, Paris, France

${ }^{2}$ Economic Innovation Group,

Washington, DC, USA

${ }^{3}$ Microsoft Corporation, Microsoft Research,

Redmond, WA, USA

${ }^{4}$ The Dartmouth Institute,

Lebanon, NH, USA

${ }^{5}$ Kellogg School of Business,

Evanston, IL, USA

${ }^{6}$ Amos Tuck School of Business,

Hanover, NH, USA

Corresponding Author: William B. Weeks, $M D, P h D, M B A ;$ Microsoft Corporation, Microsoft Research, Redmond, WA, USA (e-mail: william.weeks@microsoft.com).
Funding Mr. Wallace was funded by the US-France Fulbright Commission in Paris, France.

\section{Compliance with Ethical Standards:}

Conflict of Interest: The authors declare that they do not have a conflict of interest.

\section{REFERENCES}

1. Weeks WB, Cao SY, Lester CM, Weinstein JN, Morden NE. Association Between Community Economic Distress and Receipt of Recommended Services Among Medicare Fee-for-Service Enrollees. J Gen Intern Med. 2019;34:2731-2.

2. Weeks WB, Ouayogodé MHL, Ventelou B, Mackenzie T, Weinstein JN. Community Economic Distress and Changes in Medicare Patients' End-ofLife Care Costs. J Palliat Med. 2018;21:742-3.

3. Weeks WB, Ouayogodé MHL, Weinstein JN. Association Between a Measure of Community Economic Distress and Medicare Patients' Health Care Utilization, Quality, Outcomes, and Costs. J Gen Intern Med. 2018;33:1433-5.

4. Dartmouth Atlas Project, Data Dowloads. https://atlasdata.dartmouth. edu/downloads. Accessed 15 Aug 2020.

5. Weeks WB, Huynh GH, Weinstein JN. A Decade of Modest Convergence in Geographic Variation in Per Capita Medicare Fee-for-Service Expenditures: Taxation Without Representation Is Not Sustainable; Is It Time for Taxpayer and Consumer Engagement? J Gen Intern Med 2020 35(12): 3736-9. https://doi.org/10.1007/s11606-020-05702-8.

6. State of the Opportunity Zones Marketplace: the Impact of COVID-19. Findings from EIG's national survey of Opportunity Zones stakeholders. https://eig.org/news/state-of-the-opportunity-zones-marketplace-oz-survey. Accessed 8/15/2020.

Publisher's Note: Springer Nature remains neutral with regard to jurisdictional claims in published maps and institutional affiliations. 